\title{
Role of the IL-33/ST2 receptor axis in ovarian cancer progression (Review)
}

\author{
NING LIU ${ }^{1}$, JINTONG CHEN ${ }^{2}$, YINGHUA ZHAO ${ }^{2}$, MINGYUE ZHANG $^{1}$, \\ LI PIAO $^{1}$, SIQING WANG $^{2 *}$ and YING YUE ${ }^{1^{*}}$ \\ Departments of ${ }^{1}$ Gynecological Oncology and ${ }^{2}$ Cancer Immunology, \\ The First Hospital of Jilin University, Changchun, Jilin 130061, P.R. China
}

Received April 11, 2020; Accepted November 26, 2020

DOI: 10.3892/ol.2021.12765

\begin{abstract}
Ovarian cancer remains a significant health problem for women in the world due to its diagnosis at advanced stages of disease and the high mortality rate of patients. To date, ovarian cancer is frequently treated with tumor reduction surgery followed by platinum/paclitaxel-based chemotherapy; however, most patients eventually develop relapsed disease. The mRNA expression levels of interleukin-33 (IL-33) and the suppressor of tumorigenicity 2 (ST2) receptor are significantly upregulated in ovarian cancer tissues and metastatic tumor lesions. In addition, IL-33 and ST2 expression has been associated with a poor overall survival in patients with epithelial ovarian cancer. The IL-33 receptor ST2 is expressed as both a membrane-anchored receptor (ST2L) activated by IL-33, and as a soluble variant that exhibits anti-inflammatory properties. In the present review, the functions of the IL-33/ST2L axis in cells and their aberrant expression levels in ovarian cancer were discussed. In addition, targeting their expression as a novel strategy for the control of ovarian cancer progression was emphasized.
\end{abstract}

Correspondence to: Professor Siqing Wang, Department of Cancer Immunology, The First Hospital of Jilin University, 519 Dongminzhu Street, Changchun, Jilin 130061, P.R. China E-mail:siw1970@yahoo.com

Professor Ying Yue, Department of Gynecological Oncology, The First Hospital of Jilin University, 1 Xinmin Street, Changchun, Jilin 130061, P.R. China

E-mail: yying119@126.com

*Contributed equally

Abbreviations: IL-33, interleukin-33; ST2, suppressor of tumorigenicity 2; sST2, soluble ST2; Th, T helper; DUSP5, dual-specificity phosphatase 5

Key words: IL-33, ST2, ovarian cancer, expression, signaling pathways

\section{Contents}

1. Introduction

2. Treatment approaches for ovarian cancer

3. IL-33/ST2 axis

4. IL-33 in ovarian cancer

5. Conclusion

\section{Introduction}

Ovarian cancer is the most deadly gynecologic malignancy in women worldwide due to its diagnosis at advanced stages of disease (1). There were an estimated 22,240 new cases with 14,070 deaths in the United States in 2018 (2). To date, most patients with ovarian cancer undergo tumor reduction surgery followed by chemotherapy with platinum/paclitaxel-based regimens; however, chemoresistance often develops, resulting in treatment failure and a mortality rate of $>90 \%$ (3). Thus, an improved understanding of ovarian cancer pathogenesis and the development of novel therapeutic strategies may help medical oncologists to clinically control ovarian cancer. Previous studies have shown that the mRNA expression levels of interleukin (IL)-33 and the suppressor of tumorigenicity 2 (ST2) receptor are significantly upregulated in ovarian cancer tissues and tumor metastatic lesions compared with those of normal ovarian tissues $(3,4)$. In addition, IL-33 exhibits significantly higher expression in both serous and mucinous ovarian malignancies compared with in benign ones, which is associated with an increase in tumor grade (5). Other studies have reported that increased IL-33 and ST2 expression is associated with a shortened survival time of patients with epithelial ovarian cancer $(4,6)$. The IL-33 receptor ST2 is expressed as both a membrane-anchored receptor (ST2L) activated by IL-33, and as a soluble variant (sST2) that exhibits anti-inflammatory properties (7). In the present review, the importance of the IL-33/ST2L axis in the progression of ovarian cancer was discussed, as well as the therapeutic approaches to control the IL-33/ST2L axis for patients with ovarian cancer.

\section{Treatment approaches for ovarian cancer}

The worldwide incidence and mortality rates of ovarian cancer have increased to $41.2 \%$ during the past decades from 1990 
to 2010 (8). The high-risk groups for ovarian cancer include women who have not given birth to children (9), women with early first menstruation or late menopause (10), obesity, patients treated with hormone replacement therapy (11) and carriers of germline BRCA1 or BRCA2 mutations (12). The high mortality rate is mainly due to its diagnosis at advanced stages of the disease, with $<20 \%$ of patients with ovarian cancer diagnosed at early stages (1).

Resection surgery, chemotherapy and radiotherapy are the primary options to treat ovarian cancer clinically; however, frequent recurrence of advanced ovarian cancer after chemoradiation therapy remains a clinical challenge (13). Altered tumor cell metabolism has drawn much attention as one of the causes of cancer chemoresistance; for example, cancer stem cells are known to be highly chemo-resistant and to maintain survival by altering key metabolic pathways (14). Therefore, the combination of chemotherapeutic agents with immune-targeting methods is a promising approach for overcoming drug resistance (15). For example, patients with advanced ovarian cancer in remission treated with cyclophosphamide-modulated vaccination had a trend towards improvement in survival compared with those treated with vaccination alone (16). In addition, accumulated evidence revealed that cancer stem cells serve a role in disease relapse after chemotherapy (1). Moreover, patients with ovarian cancer with BRCA1 or BRCA2 mutations exhibit an improved response rate to platinum/paclitaxel chemotherapy compared with non-carriers $(17,18)$. Furthermore, hormonal therapy and immunotherapy $(19,20)$, as well as palliative care, are also utilized to treat ovarian cancer (21).

Epithelial ovarian cancer is considered as an immunogenic tumor that can be recognized by the immune system of patients (22). Previous studies have reported that tumor-activated $\mathrm{T}$ lymphocytes and antibodies can be detected in the blood, tumor and ascite samples of patients with advanced-stage ovarian cancer $(23,24)$. The recruitment of regulatory $\mathrm{T}$ lymphocytes (Tregs) into the ovarian cancer microenvironment confers immunity privilege and is associated with a poor prognosis and a decreased survival (25). Additionally, high mRNA expression levels of programmed death-ligand 1 are associated with a poor prognosis in epithelial ovarian cancer (26). These altered immune responses serve an important role in ovarian cancer pathogenesis and disease progression. Thus, new and more effective immunotherapies may provide a novel option to treat ovarian cancer, although this treatment remains to be assessed clinically (27).

\section{IL-33/ST2 axis}

IL-33 was originally identified in canine vasospastic cerebral arteries following subarachnoid hemorrhage (28) and subsequently in human tissues in 2003 (29). In 2005, IL-33 was identified as a member of the IL-1 superfamily of cytokines and as a ligand of ST2 (30). The IL33 gene is localized at human chromosome 9p24.1, and IL-33 cDNA encodes polypeptides of 270 amino acid in humans, with a protein mass of $30 \mathrm{kDa}$ (31). IL-33 protein is composed of two evolutionary conserved domains: The amino (N)-terminal nuclear domain and the carboxyl (C)-terminal IL-1-like cytokine domain (32). It has been demonstrated that the N-terminal part of IL-33 is necessary for the nuclear targeting of epitope tagged (GFP-fused) IL-33 and for translocating IL-33 (tagged with $\mathrm{N}$-term-discosoma recombinant red fluorescent protein) to the nucleus in a mouse model $(33,34)$. Regarding the $\mathrm{C}$-terminal IL-1-like cytokine domain of IL-33, this has a $\beta$-trefoil fold that interacts with the extracellular domain of ST2, thereby exerting the cytokine function of IL-33 (35).

IL-33 is expressed in dendritic cells, B cells, T helper (Th)1 cells, $\mathrm{CD}^{+} \mathrm{T}$ cells, natural killer cells, neutrophils and macrophages $(36,37)$. IL-33, as a member of the IL-1 family, functions to induce production of Th2-associated cytokines in Th2 cells, mast cells, eosinophils and basophils after binding and activating ST2 (30,38). ST2, also called IL-1 receptor-like 1, is an interleukin-1 receptor family glycoprotein (39). To date, three isoforms of ST2 have been identified, including a full-length transmembrane isoform ST2L, a soluble form sST2 and a novel variant ST2V of undetermined localization $(31,40)$. The sST2 lacks the transmembrane domain and binds to IL-33 as a decoy receptor, which possesses anti-inflammatory properties $(7,41)$ in the human body.

IL-33 is a dual function protein that acts intracellularly as a nuclear factor regulating transcription and extracellularly as a potent cytokine (42). Full-length IL-33 can target the nucleus to bind to histones $\mathrm{H} 2 \mathrm{~A}$ and $\mathrm{H} 2 \mathrm{~B}$ as a chromatin-related nuclear factor $(32,43)$. In addition, IL-33 can repress the expression levels of $\mathrm{NF}-\kappa \mathrm{B}$-regulated genes that are necessary for pro-inflammatory signaling by interacting with the $\mathrm{N}$-terminal domain of the p65 subunit of NF- $\kappa \mathrm{B}$ (44). A study in multiple sclerosis revealed that IL-33 can activate histone deacetylase 3 activities, thereby affecting gene expression through remodeling chromatin structure and epigenetic mechanisms (45).

Furthermore, IL-33 has been demonstrated to be a tissue-derived nuclear cytokine and is expressed in epithelial, endothelial and fibroblastlike cells under both homeostatic and inflammatory conditions (12). Additionally, IL-33 functions as a stress-response protein, since it is highly expressed in the nucleus of endothelial and epithelial cells after damage or infection with a pathogen, resulting in its release from the nucleus to the extracellular space as an endogenous 'danger' signal to alert the immune system (46-48). IL-33 is widely expressed in various organs, including the brain, heart, liver, kidney, spleen and lung (49). IL-33 possesses pleiotropic activities during Th1, Th2 and regulatory immune responses, and serves an important role in fibrotic, infectious and chronic inflammatory diseases (36). IL-33 functions to promote or inhibit disease progression depending on the disease type (31). For example, IL-33 mRNA expression is significantly increased in the inflammatory mucosa of patients with inflammatory bowel disease and in mice with dextran sulfate sodium-induced colitis (50). In addition, previous studies have revealed that the IL-33/ST2 axis demonstrates an adverse effect on the pathogenesis of systemic lupus erythematosus (51), as well as promoting tubular cell injury and interstitial fibrosis in obstructive kidney disease (52). Moreover, the serum levels of IL-33 and sST2 are elevated in patients with sepsis, suggesting the involvement of the IL-33/ST2 axis in the pathogenesis and progression of sepsis (53-55). Another study has demonstrated that IL-33 expression is upregulated in the serum and synovial fluid samples of patients with 


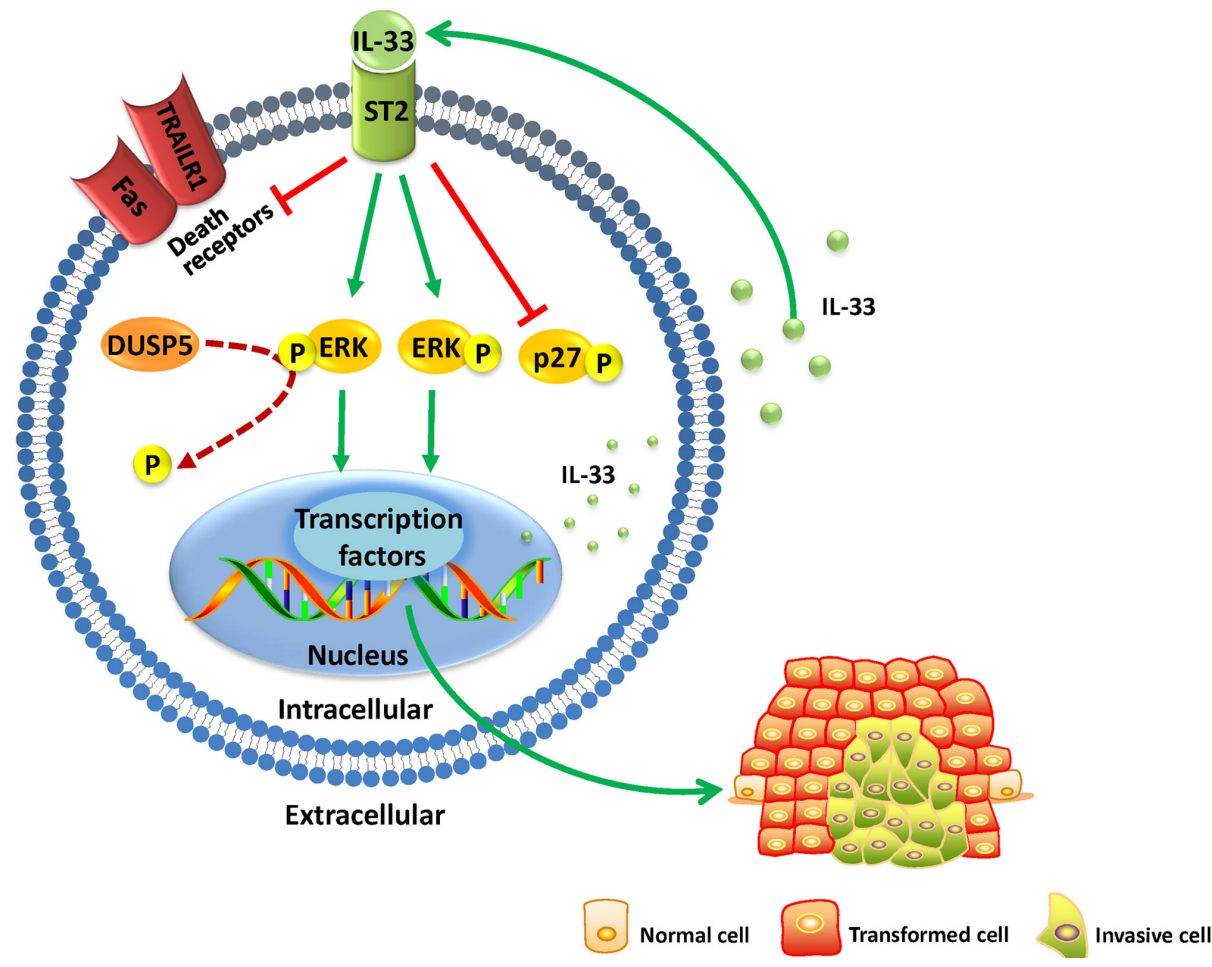

Figure 1. Possible role of IL-33 signaling pathways in ovarian cancer cells. Low DUSP5 expression decreases the dephosphorylation of ERK, thereby increasing IL-33 expression. IL-33 promotes the proliferation and inhibits the apoptosis of ovarian cancer cells by downregulating p27, Fas and TRAILR1 in vitro. IL-33, interleukin-33; Fas, Fas cell surface death receptor; TRAILR1, tumor necrosis factor-related apoptosis-inducing ligand receptor 1; DUSP5, dual-specificity phosphatase 5; P, phosphoryl group; ST2, suppressor of tumorigenicity 2.

rheumatoid arthritis and is associated with disease progression (56). However, IL-33 and ST2 expression is beneficial in a non-alcoholic fatty liver disease mouse model primarily by decreasing high-flow dialysis-induced hepatic steatosis and serum alanine aminotransferase levels, while improving insulin resistance and glucose tolerance (31).

In human cancer, the IL-33/ST2 axis promotes lung cancer cell migration and invasion through the protein kinase B pathway (57). In addition, IL-33 expression is upregulated in the serum of patients with gastric (58), non-small cell lung (59) and breast cancer (60). By contrast, IL-33 possesses a tumor-suppressor role in sporadic colon cancer; the IL-33/ST2 axis regulates the tumor microenvironment by recruiting immune cells that support malignant hyperplasia or alter antitumor immunity (61). In addition, IL-33/ST2L signals trigger the transcription of downstream inflammatory genes and anti-inflammatory genes by activating various intracellular kinases and factors, thereby activating the inflammatory immune response (62). The latest data indicate that the IL33/ST2 axis in Tregs is an important pathway that allows Tregs to accumulate in the tumor microenvironment, suggesting that the IL33/ST2 axis may be a potential therapeutic target for cancer immunotherapy (63). Overall, the aforementioned studies demonstrate the pleiotropy of IL-33 in regulating antitumor immunity or tumor growth.

\section{IL-33 in ovarian cancer}

IL-33 expression fluctuates with specific ovarian functions, such as ovulation and estrus cycles (64). Studies have revealed that IL-33 is the most significantly upregulated immune mole- cule during ovulation $(64,65)$. Numerous randomly sampled ovaries expressed a higher level of IL-33 compared with other organs, except with ovaries sampled at IL-33 expression peak in the estrous cycle and during ovulation (64). This suggests that some additional unknown factors may affect IL-33 expression. It has been revealed that IL-33 expression is significantly upregulated in ovarian cancer tissues and metastatic tumor lesions compared with in benign ones (5). In addition, compared with in normal human ovarian tissue samples, upregulation of ST2 was detected in $66 \%$ primary ovarian tumors and $87 \%$ metastatic ovarian tumors, which was more marked than the upregulation of IL-33 expression in 59\% of primary sites and $76 \%$ of metastatic ovarian tumors (6). Another study has demonstrated that high IL-33 and ST2 expression is closely associated with a poor overall survival of patients with epithelial ovarian cancer (6), indicating that the altered expression of the IL-33/ST2 axis serves an important role in the progression of ovarian cancer and that the detection of their expression may be utilized as a biomarker for a poor prognosis in patients with ovarian cancer.

Since $70 \%$ of ovarian cancers are diagnosed at advanced stages of disease with metastasized tumors, it is crucial to assess and investigate the molecular mechanisms involved in the invasiveness and metastasis of ovarian cancer $(66,67)$. A previous study has analyzed the microarray data from the Gene Expression Omnibus comprehensive database and found that patients with low dual-specificity phosphatase 5 (DUSP5) expression have significantly shorter overall survival than those with high expression (68). DUSP5 is a nuclear ERK1/2-selective phosphatase induced by ERK signaling in mammalian cells, which selectively binds and inactivates 
ERK1 and ERK2 in vivo, and is a direct transcriptional target of the tumor suppressor p53 (69-71). The latest data indicate that silencing of DUSP5 transcription is able to increase the expression and secretion of IL-33, thereby promoting the proliferation, migration and invasion of ovarian cancer cells (68). Furthermore, a previous study has revealed changes in signal transduction pathways after treatment of epithelial ovarian cancer cells with full-length human IL-33, with increased phosphorylation of JNK and ERK proteins; however, after using sST2 to neutralize IL-33, the phosphorylation of ERK and JNK was completely blocked (6). By contrast, treatment of human ovarian cancer CAOV3 and HO8910 cells with the selective ERK inhibitor U0126 significantly suppressed ERK phosphorylation, blocking the effects of IL-33-mediated increase in tumor cell migration and invasion, as well as tumor cell viability and proliferation (6). Additionally, the JNK pathway inhibitor SP600125 inhibited JNK phosphorylation in CAOV3 and HO8910 cells, but had no effect on IL-33-induced cell migration and invasion, even though they were able to block tumor cell viability and proliferation in IL-33-induced CAOV3 cells (6). Furthermore, a recent study reported that IL-33 promoted the proliferation and inhibited the apoptosis of ovarian cancer cells by downregulating p27, Fas cell surface death receptor and tumor necrosis factor-related apoptosis-inducing ligand receptor 1 (TRAILR1) in vitro (4). The aforementioned studies indicated that low DUSP5 expression decreases the dephosphorylation of ERK, thereby increasing IL-33 expression, which promotes tumor cell invasion and metastasis through the phosphorylation of ERK and the other aforementioned pathways. In summary, low DUSP5 expression may decrease the dephosphorylation of ERK, thereby increasing IL-33 expression; IL-33 may then promote the proliferation of ovarian cancer cells and inhibit their apoptosis by downregulating p27, Fas and TRAILR1 expression. This process may lead to the survival of patients with low DUSP5 expression to be shorter than those with high expression (Fig. 1). However, the precise underlying mechanism of IL-33/ST2-promoting tumor growth and metastasis remains to be determined.

In addition, further investigations regarding the conflicting functions of IL-33 in different types of cancer are required. For example, one study has revealed that IL-33 is a key mediator in the development of inflammation-associated pancreatic cancer by upregulating the secretion of pro-inflammatory IL-6 and IL-8 (72), whereas another study has reported that transgenic IL-33 was able to activate natural killer and $\mathrm{CD}^{+} \mathrm{T}$ cells to inhibit the growth and metastasis of melanoma and lung cancer in animal models (73). However, in ovarian cancer, studies have demonstrated that a local intraperitoneal injection of IL-33 is able to delay ovarian cancer peritoneal metastases, indicating the efficacy of IL-33 for the treatment of abdominal metastatic cancer $(74,75)$.

\section{Conclusion}

Nearly 30 years have passed since the discovery of IL-33, and numerous studies have been conducted to determine the molecular structure, distribution, receptor binding and signaling pathways of IL-33. The knowledge regarding the molecular basis of IL-33 signaling is relatively comprehensive. To date, the literature presents great progress in understanding the function of IL-33 in ovarian cancer. However, future studies are required to fully understand the role of IL-33 in the regulation of signaling pathways and regulatory networks in ovarian cancer. Targeting IL-33 and its signaling pathways may function as a novel strategy to control ovarian cancer progression.

\section{Acknowledgements}

Not applicable.

\section{Funding}

No funding was received.

\section{Availability of data and materials}

Not applicable.

\section{Authors' contributions}

NL, YY and SW conceived and designed the study. NL, JC, YZ, MZ and LP performed the literature search and drafted the manuscript. All authors read and approved the final manuscript.

\section{Ethics approval and consent to participate}

Not applicable.

\section{Patient consent for publication}

Not applicable.

\section{Competing interests}

The authors declare that they have no competing interests.

\section{References}

1. Li SS, Ma J and Wong AST: Chemoresistance in ovarian cancer: Exploiting cancer stem cell metabolism. J Gynecol Oncol 29: e32, 2018

2. Siegel RL, Miller KD and Jemal A: Cancer statistics, 2018. CA Cancer J Clin 68: 7-30, 2018.

3. Agarwal R and Kaye SB: Ovarian cancer: Strategies for overcoming resistance to chemotherapy. Nat Rev Cancer 3: 502-516, 2003.

4. Liu X, Hansen DM, Timko NJ, Zhu Z, Ames A, Qin C, Nicholl MB, Bai Q, Chen X, Wakefield MR, et al: Association between interleukin-33 and ovarian cancer. Oncol Rep 41: 1045-1050, 2019.

5. Saied EM and El-Etreby NM: The role and prognostic value of inducible nitric oxide synthase (iNOS) and interleukin-33 (IL-33) in serous and mucinous epithelial ovarian tumours. Ann Diagn Pathol 27: 62-68, 2017.

6. Tong X, Barbour M, Hou K, Gao C, Cao S, Zheng J, Zhao Y, $\mathrm{Mu} \mathrm{R}$ and Jiang HR: Interleukin-33 predicts poor prognosis and promotes ovarian cancer cell growth and metastasis through regulating ERK and JNK signaling pathways. Mol Oncol 10: 113-125, 2016.

7. De la Fuente M, MacDonald TT and Hermoso MA: The IL-33/ST2 axis: Role in health and disease. Cytokine Growth Factor Rev 26: 615-623, 2015. 
8. Lozano R, Naghavi M, Foreman K, Lim S, Shibuya K, Aboyans V, Abraham J, Adair T, Aggarwal R, Ahn SY, et al: Global and regional mortality from 235 causes of death for 20 age groups in 1990 and 2010: A systematic analysis for the Global Burden of Disease Study 2010. Lancet 380: 2095-2128, 2012.

9. Hoffman Bl SJ, Schaffer JI, Halvorson LM, Bradshaw KD and Cunningham FG: Epithelian ovarian cancer. In: Williams Gynecology. 2nd edition. McGraw-Hill, New York, NY, pp. 853-878, 2012

10. Gong TT, Wu QJ, Vogtmann E, Lin B and Wang YL: Age at menarche and risk of ovarian cancer: A meta-analysis of epidemiological studies. Int J Cancer 132: 2894-2900, 2013.

11. Longo DL, Fauci A, Kasper D, Hauser S, Jameson JL and Loscalzo J: Harrison's Principles of Internal Medicine. 18th edition. McGraw-Hill, New York, NY, 2012.

12. Kanchi KL, Johnson KJ, Lu C, McLellan MD, Leiserson MD Wendl MC, Zhang Q, Koboldt DC, Xie M, Kandoth C, et al: Integrated analysis of germline and somatic variants in ovarian cancer. Nat Commun 5: 3156, 2014.

13. Coleman RL, Monk BJ, Sood AK and Herzog TJ: Latest research and treatment of advanced-stage epithelial ovarian cancer. Nat Rev Clin Oncol 10: 211-224, 2013.

14. Deshmukh A, Deshpande K, Arfuso F, Newsholme P and Dharmarajan A: Cancer stem cell metabolism: A potential target for cancer therapy. Mol Cancer 15: 69, 2016.

15. Chen G and Emens LA: Chemoimmunotherapy: Reengineering tumor immunity. Cancer Immunol Immunother 62: 203-216, 2013.

16. Chu CS, Boyer J, Schullery DS, Gimotty PA, Gamerman V, Bender J, Levine BL, Coukos G, Rubin SC, Morgan MA, et al: Phase I/II randomized trial of dendritic cell vaccination with or without cyclophosphamide for consolidation therapy of advanced ovarian cancer in first or second remission. Cancer Immunol Immunother 61: 629-641, 2012.

17. Hyman DM, Zhou Q, Iasonos A, Grisham RN, Arnold AG, Phillips MF, Bhatia J, Levine DA, Aghajanian C, Offit $\mathrm{K}$, et al: Improved survival for BRCA2-associated serous ovarian cancer compared with both BRCA-negative and BRCA1-associated serous ovarian cancer. Cancer 118 3703-3709, 2012

18. Yang D, Khan S, Sun Y, Hess K, Shmulevich I, Sood AK and Zhang W: Association of BRCA1 and BRCA2 mutations with survival, chemotherapy sensitivity, and gene mutator phenotype in patients with ovarian cancer. JAMA 306 : $1557-1565,2011$.

19. Kanduc D: Oligopeptides for immunotherapy approaches in ovarian cancer treatment. Curr Drug Discov Technol 16 : 285-289, 2019.

20. Argento M, Hoffman P and Gauchez AS: Ovarian cancer detection and treatment: Current situation and future prospects. Anticancer Res 28 (5B): 3135-3138, 2008.

21. Jayson GC, Kohn EC, Kitchener HC and Ledermann JA: Ovarian cancer. Lancet 384: 1376-1388, 2014.

22. Zhang L, Conejo-Garcia JR, Katsaros D, Gimotty PA, Massobrio M, Regnani G, Makrigiannakis A, Gray H, Schlienger K, Liebman MN, et al: Intratumoral T cells, recurrence, and survival in epithelial ovarian cancer. N Engl J Med 348: 203-213, 2003

23. Schlienger K, Chu C S, Woo E Y, Rivers P M, Toll A J, Hudson B Maus MV, Riley JL, Choi Y, Coucos G, et al.TRANCE- and CD40 ligand-matured dendritic cells reveal MHC class I-restricted T cells specific for autologous tumor in late-stage ovarian cancer patients. Clin Cancer Res 9: 1517-1527, 2003.

24. Goodell V, Salazar LG, Urban N, Drescher CW, Gray H, Swensen RE, McIntosh MW and Disis ML: Antibody immunity to the p53 oncogenic protein is a prognostic indicator in ovarian cancer. J Clin Oncol 24: 762-768, 2006.

25. Curiel TJ, Coukos G, Zou L, Alvarez X, Cheng P, Mottram P Evdemon-Hogan M, Conejo-Garcia JR, Zhang L, Burow M, et al: Specific recruitment of regulatory $\mathrm{T}$ cells in ovarian carcinoma fosters immune privilege and predicts reduced survival. Nat Med 10: 942-949, 2004.

26. Hamanishi J, Mandai M, Iwasaki M, Okazaki T, Tanaka Y, Yamaguchi K, Higuchi T, Yagi H, Takakura K, Minato N, et al: Programmed cell death 1 ligand 1 and tumor-infiltrating $\mathrm{CD} 8^{+} \mathrm{T}$ lymphocytes are prognostic factors of human ovarian cancer. Proc Natl Acad Sci USA 104: 3360-3365, 2007.

27. Hardwick N, Frankel PH and Cristea M: New approaches for immune directed treatment for ovarian cancer. Curr Treat Options Oncol 17: 14, 2016.
28. Onda H, Kasuya H, Takakura K, Hori T, Imaizumi T, Takeuchi T, Inoue I and Takeda J: Identification of genes differentially expressed in canine vasospastic cerebral arteries after subarachnoid hemorrhage. J Cereb Blood Flow Metab 19: $1279-1288,1999$.

29. Baekkevold ES, Roussigné M, Yamanaka T, Johansen FE, Jahnsen FL, Amalric F, Brandtzaeg P, Erard M, Haraldsen G and Girard JP: Molecular characterization of NF-HEV, a nuclear factor preferentially expressed in human high endothelial venules. Am J Pathol 163: 69-79, 2003.

30. Schmitz J, Owyang A, Oldham E, Song Y, Murphy E, McClanahan TK, Zurawski G, Moshrefi M, Qin J, Li X, et al: IL-33, an interleukin-1-like cytokine that signals via the IL-1 receptor-related protein ST2 and induces T helper type 2-associated cytokines. Immunity 23: 479-490, 2005.

31. Sun Z, Chang B, Gao M, Zhang J and Zou Z: IL-33-ST2 axis in liver disease: Progression and challenge. Mediators Inflamm 2017: 5314213, 2017

32. Roussel L, Erard M, Cayrol C and Girard JP: Molecular mimicry between IL-33 and KSHV for attachment to chromatin through the H2A-H2B acidic pocket. EMBO Rep 9: 1006-1012, 2008.

33. Bessa J, Meyer CA, de Vera Mudry MC, Schlicht S, Smith SH, Iglesias A and Cote-Sierra J: Altered subcellular localization of IL-33 leads to non-resolving lethal inflammation. J Autoimmun 55: 33-41, 2014.

34. Xi H, Katschke KJ Jr, Li Y, Truong T, Lee WP, Diehl L, Rangell L, Tao J, Arceo R, Eastham-Anderson J, et al: IL-33 amplifies an innate immune response in the degenerating retina. J Exp Med 213: 189-207, 2016.

35. Liu X, Hammel M, He Y, Tainer JA, Jeng US, Zhang L, Wang S and Wang X: Structural insights into the interaction of IL-33 with its receptors. Proc Natl Acad Sci USA 110: 14918-14923, 2013.

36. Cayrol C and Girard JP: Interleukin-33 (IL-33): A nuclear cytokine from the IL-1 family. Immunol Rev 281: 154-168, 2018.

37. Cayrol C and Girard JP: IL-33: An alarmin cytokine with crucial roles in innate immunity, inflammation and allergy. Curr Opin Immunol 31: 31-37, 2014.

38. Mirchandani AS, Salmond RJ and Liew FY: Interleukin-33 and the function of innate lymphoid cells. Trends Immunol 33: 389-396, 2012

39. Lingel A, Weiss TM, Niebuhr M, Pan B, Appleton BA, Wiesmann C, Bazan JF and Fairbrother WJ: Structure of IL-33 and its interaction with the ST2 and IL-1RAcP receptors-insight into heterotrimeric IL-1 signaling complexes. Structure 17: 1398-1410, 2009

40. Tago K, Noda T, Hayakawa M, Iwahana H, Yanagisawa K, Yashiro $\mathrm{T}$ and Tominaga S: Tissue distribution and subcellular localization of a variant form of the human ST2 gene product, ST2V. Biochem Biophys Res Commun 285: 1377-1383, 2001.

41. Iwahana H, Yanagisawa K, Ito-Kosaka A, Kuroiwa K, Tago K, Komatsu N, Katashima R, Itakura M and Tominaga S: Different promoter usage and multiple transcription initiation sites of the interleukin-1 receptor-related human ST2 gene in UT-7 and TM12 cells. Eur J Biochem 264: 397-406, 1999.

42. Larsen KM, Minaya MK, Vaish V and Peña MMO: The role of IL-33/ST2 pathway in tumorigenesis. Int J Mol Sci 19: E2676, 2018.

43. Carriere V, Roussel L, Ortega N, Lacorre DA, Americh L, Aguilar L, Bouche G and Girard JP: IL-33, the IL-1-like cytokine ligand for ST2 receptor, is a chromatin-associated nuclear factor in vivo. Proc Natl Acad Sci (USA) 104: 282-287, 2007.

44. Ali S, Mohs A, Thomas M, Klare J, Ross R, Schmitz ML and Martin MU: The dual function cytokine IL-33 interacts with the transcription factor NF- $\kappa \mathrm{B}$ to dampen NF- $\kappa \mathrm{B}$-stimulated gene transcription. J Immunol 187: 1609-1616, 2011.

45. Zhang F, Tossberg JT, Spurlock CF, Yao SY, Aune TM and Sriram S: Expression of IL-33 and its epigenetic regulation in Multiple Sclerosis. Ann Clin Transl Neurol 1: 307-318, 2014.

46. Monticelli LA, Sonnenberg GF, Abt MC, Alenghat T, Ziegler CG, Doering TA, Angelosanto JM, Laidlaw BJ, Yang CY, Sathaliyawala T, et al: Innate lymphoid cells promote lung-tissue homeostasis after infection with influenza virus. Nat Immunol 12: 1045-1054, 2011.

47. Chang YJ, Kim HY, Albacker LA, Baumgarth N, McKenzie AN, Smith DE, Dekruyff RH and Umetsu DT: Innate lymphoid cells mediate influenza-induced airway hyper-reactivity independently of adaptive immunity. Nat Immunol 12: 631-638, 2011. 
48. Yasuda K, Muto T, Kawagoe T, Matsumoto M, Sasaki Y, Matsushita K, Taki Y, Futatsugi-Yumikura S, Tsutsui H, Ishii KJ, et al: Contribution of IL-33-activated type II innate lymphoid cells to pulmonary eosinophilia in intestinal nematode-infected mice. Proc Natl Acad Sci (USA) 109 3451-3456, 2012

49. Chen WY, Li LC and Yang JL: Emerging roles of IL-33/ST2 axis in renal diseases. Int J Mol Sci 18: E783, 2017.

50. Sun M, He C, Wu W, Zhou G, Liu F, Cong Y and Liu Z: Hypoxia inducible factor-1 $\alpha$-induced interleukin-33 expression in intestinal epithelia contributes to mucosal homeostasis in inflammatory bowel disease. Clin Exp Immunol 187: 428-440, 2017.

51. Yu SL, Wong CK and Tam LS: The alarmin functions of high-mobility group box-1 and IL-33 in the pathogenesis of systemic lupus erythematosus. Expert Rev Clin Immunol 9: 739-749, 2013

52. Chen WY, Chang YJ, Su CH, Tsai TH, Chen SD, Hsing CH and Yang JL: Upregulation of interleukin-33 in obstructive renal injury. Biochem Biophys Res Commun 473: 1026-1032, 2016.

53. Çekmez F, Fidanci MK, Ayar G, Saldir M, Karaoglu A, Gündüz RC, Tunc T and Kalkan G: Diagnostic value of upar, IL-33, and ST2 Levels in childhood sepsis. Clin Lab 62: 751-755, 2016.

54. Parenica J, Malaska J, Jarkovsky J, Lipkova J, Dastych M, Helanova K, Litzman J, Tomandl J, Littnerova S, Sevcikova J, et al: Soluble ST2 levels in patients with cardiogenic and septic shock are not predictors of mortality. Exp Clin Cardiol 17: 205-209, 2012.

55. Xu H, Turnquist HR, Hoffman R and Billiar TR: Role of the IL-33-ST2 axis in sepsis. Mil Med Res 4: 3, 2017.

56. Matsuyama Y, Okazaki H, Tamemoto H, Kimura H, Kamata Y, Nagatani K, Nagashima T, Hayakawa M, Iwamoto M, Yoshio T, et al: Increased levels of interleukin-33 in sera and synovial fluid from patients with active rheumatoid arthritis. J Rheumatol 37: 18-25, 2010.

57. Yang Z, Gao X, Wang J, Xu L, Zheng Y and Xu Y: Interleukin-33 enhanced the migration and invasiveness of human lung cancer cells. OncoTargets Ther 11: 843-849, 2018.

58. Sun P, Ben Q, Tu S, Dong W, Qi X and Wu Y: Serum interleukin-33 levels in patients with gastric cancer. Dig Dis Sci 56: 3596-3601, 2011.

59. Hu LA, Fu Y, Zhang DN and Zhang J: Serum IL-33 as a diagnostic and prognostic marker in non- small cell lung cancer. Asian Pac J Cancer Prev 14: 2563-2566, 2013.

60. Liu J, Shen JX, Hu JL, Huang WH and Zhang GJ: Significance of interleukin-33 and its related cytokines in patients with breast cancers. Front Immunol 5: 141, 2014.

61. Eissmann MF, Dijkstra C, Wouters MA, Baloyan D, Mouradov D, Nguyen PM, Davalos-Salas M, Putoczki TL, Sieber OM, Mariadason JM, et al: Interleukin-33 signaling restrains sporadic colon cancer in an interferon- $\gamma$-dependent manner. Cancer Immunol Res 6: 409-421, 2018.

62. Casciaro M, Cardia R, Di Salvo E, Tuccari G, Ieni A and Gangemi S: Interleukin-33 involvement in nonsmall cell lung carcinomas: An update. Biomolecules 9: E203, 2019.
63. Son J, Cho JW, Park HJ, Moon J, Park S, Lee H, Lee J, Kim G, Park SM, Lira SA, et al: Tumor-infiltrating regulatory T-cell accumulation in the tumor microenvironment is mediated by IL33/ST2 signaling. Cancer Immunol Res 8: 1393-1406, 2020.

64. Carlock CI, Wu J, Zhou C, Tatum K, Adams HP, Tan F and Lou Y: Unique temporal and spatial expression patterns of IL-33 in ovaries during ovulation and estrous cycle are associated with ovarian tissue homeostasis. J Immunol 193: 161-169, 2014

65. Wu J, Carlock C, Zhou C, Nakae S, Hicks J, Adams HP and Lou Y: IL-33 is required for disposal of unnecessary cells during ovarian atresia through regulation of autophagy and macrophage migration. J Immunol 194: 2140-2147, 2015.

66. Goff BA, Mandel L, Muntz HG and Melancon CH: Ovarian carcinoma diagnosis. Cancer 89: 2068-2075, 2000.

67. Heintz AP, Odicino F, Maisonneuve P, Quinn MA, Benedet JL, Creasman WT, Ngan HY, Pecorelli S and Beller U: Carcinoma of the ovary. FIGO 26th annual report on the results of treatment in gynecological cancer. Int J Gynaecol Obstet 95 (Suppl 1): S161-S192, 2006

68. Wang L, Hu J, Qiu D, Gao H, Zhao W, Huang Y, Jiang T, Zhou J and Chen Y: Dual-specificity phosphatase 5 suppresses ovarian cancer progression by inhibiting IL-33 signaling. Am J Transl Res 11: 844-854, 2019.

69. Rushworth LK, Kidger AM, Delavaine L, Stewart G, van Schelven S, Davidson J, Bryant CJ, Caddye E, East P, Caunt CJ, et al: Dual-specificity phosphatase 5 regulates nuclear ERK activity and suppresses skin cancer by inhibiting mutant Harvey-Ras (HRasQ61L)-driven SerpinB2 expression. Proc Natl Acad Sci (USA) 111: 18267-18272, 2014

70. Kutty RG, Talipov MR, Bongard RD, Lipinski RAJ, Sweeney NL, Sem DS, Rathore R and Ramchandran R: Dual specificity phosphatase 5-substrate interaction: A mechanistic perspective. Compr Physiol 7: 1449-1461, 2017.

71. Zhang H, Zheng H, Mu W, He Z, Yang B, Ji Y and Hui L: DUSP16 ablation arrests the cell cycle and induces cellular senescence. FEBS J 282: 4580-4594, 2015.

72. Schmieder A, Multhoff G and Radons J: Interleukin-33 acts as a pro-inflammatory cytokine and modulates its receptor gene expression in highly metastatic human pancreatic carcinoma cells. Cytokine 60: 514-521, 2012.

73. Gao X, Wang X, Yang Q, Zhao X, Wen W, Li G, Lu J, Qin W, Qi Y, Xie F, et al: Tumoral expression of IL-33 inhibits tumor growth and modifies the tumor microenvironment through CD8 ${ }^{+} \mathrm{T}$ and NK cells. J Immunol 194: 438-445, 2015.

74. Perales-Puchalt A, Svoronos N, Villarreal DO, Zankharia U, Reuschel E, Wojtak K, Payne KK, Duperret EK, Muthumani K, Conejo-Garcia JR, et al: IL-33 delays metastatic peritoneal cancer progression inducing an allergic microenvironment. OncoImmunology 8: e1515058, 2018.

75. Melichar B and Freedman R S. Immunology of the peritoneal cavity: Relevance for host-tumor relation. Int J Gynecol Canc 12: 3-17, 2012. 